\title{
Giant hepatic hemangioma
}

\section{Ranendra Hajong}

Published online: 10 March 2013

(C) Indian Society of Gastroenterology 2013

Hepatic hemangioma is the most common tumor of the liver, is composed of masses of arterial and venous connections within the liver, and usually remains asymptomatic. They may occasionally become symptomatic due to mass effect or rapid growth. Rare complications include portal hypertension, consumption coagulopathy, spontaneous or traumatic rupture, and intratumoral bleeding [1, 2]. This MRI image (Fig. 1) of the abdomen shows a huge hepatic hemangioma occupying nearly the entire abdominal cavity in a 46year-old lady who presented with gradually increasing abdominal swelling of 5 years' duration. Surgical resection was done and the patient recovered uneventfully.

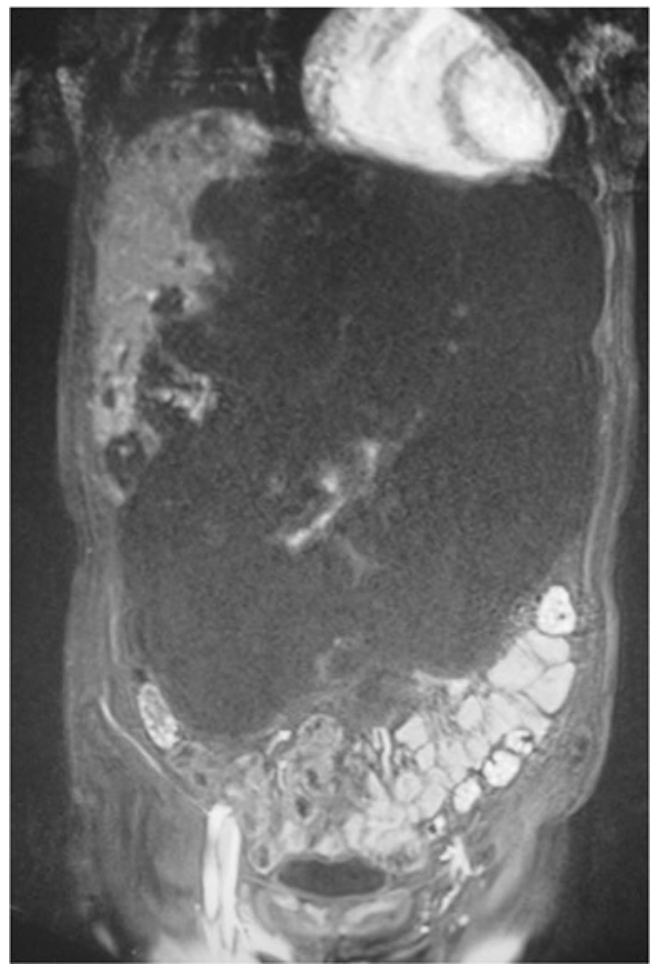

Fig. 1 Showing large hepatic hemangioma occupying nearly the whole abdominal cavity

\section{References}

1. Suzuki H, Nimura Y, Kamiya J, et al. Preoperative transcatheter arterial embolization for giant cavernous hemangioma of the liver with consumption coagulopathy. Am J Gastroenterol. 1997;92:688-91.

2. Takahashi T, Katoh H, Dohke M, Okushiba S. A giant hepatic hemangioma with secondary portal hypertension: a case report of successful surgical treatment. Hepatogastroenterology. 1997;44:1212-4. 